ConNotAs. Revista DE CRíticA Y TEORía Literarias/NúM. 14-15/2014-2015

\title{
Madre de las Historias. Idea de religión en un cuento de Alberto Chimal
}

\author{
Manuel Llanes García*
}

Resumen:

Ante la multiplicidad de definiciones que de lo fantástico existen, no con poca frecuencia contradictorias entre sí, ofrecemos, a manera de alternativa, una exposición de la filosofía de la religión del español Gustavo Bueno. Acto seguido, se pone en práctica lo dicho a propósito de un relato del narrador mexicano Alberto Chimal, "La verdad", contenido en su antología El país de los hablistas (2001). De tal forma, vamos a ver que lo dicho por el filósofo español encontrará cierta correspondencia en la obra del mencionado escritor, desde que en ambos es posible situar la aparición de lo religioso en determinadas prácticas ancestrales que, además, luego jugarán un papel determinante en el basamento de la literatura y su esencia. Por lo tanto, apelamos a una interpretación histórica referente a tres fases de la religión: primaria, secundaria y terciaria, que además sale al paso de clasificaciones muy difundidas como el rótulo "religiones del libro".

Palabras clave:

Religión, cuento fantástico, ficción literaria.

\footnotetext{
* Universidad de Sonora.
} 
Partimos del supuesto de que la religión es un fenómeno de gran trascendencia en nuestras sociedades, sin perjuicio de las posturas anticlericales también muy difundidas, aunque, en todo caso, estas últimas no harían sino probar nuestra afirmación: hay anticlericalismo ahí donde se sabe que la religión tiene fuerza, aunque esta tienda a disminuir por las razones que se quiera; otra cosa es que se cuestione su legitimidad en la organización del mundo y al atacar la religión se le devuelva al primer plano de los debates del presente. De ahí que nos parezca necesario hacer referencia a una filosofía de la religión en condiciones, en orden de interpretar de forma apropiada una compleja red de fenómenos, especialmente aquellos que tengan que ver con la literatura. Consideramos fundamental lo anterior porque, al no poseer una filosofía de la religión en el sentido en que aquí la reivindicamos, muchas veces se impone el relativismo cultural, que iguala, sin más, toda confesión; tal es el caso del estudio preliminar de José Ricardo Chaves para la antología de Amado Nervo El castillo del inconsciente, en el cual quedan ecualizadas, ${ }^{1}$

1 Chaves cita un prólogo de una antología dedicada a Nervo, en la cual su autor, Alfonso Reyes, destaca el papel preponderante que la religión tiene en el nayarita. Reyes se refiere a la práctica de la magia y el espiritismo como degeneradas, aseveración que Chaves rechaza: "Lo que sí es cuestionable en el juicio de Reyes es considerar al espiritismo y a la magia como formas impuras del sentimiento religioso, pues no se trata de una degradación; es la misma vocación de trascendencia, sólo que funcionando en un contexto histórico distinto (siglo XIX), en el que la referencia a la ciencia es aceptada cada vez más como criterio de verdad (el prejuicio 'científico = verdadero'), aspecto que el propio Reyes admite cuando habla de la ciencia mezclada con la religión como uno de los elementos de la impureza religiosa" (Nervo 11). Como puede verse, Chaves se basa en el sentimiento religioso, es decir en un factor psicológico, para poner en pie de igualdad a la religión propiamente dicha y otras prácticas. También es verdad que Bueno mismo nos llama la atención acerca de que no podemos llamar a manifestaciones como la magia y espiritismo "sucedáneos" de la religión (eso nos situaría en una perspectiva sectaria, como si habláramos desde el cristianismo): más correcto es hablar de una refluencia de ese tipo de prácticas, en tanto que su fortalecimiento puede coincidir con un debilitamiento del cristianismo, que bien podría haberlas mantenido bajo control (Bueno, Animal 293). 
sin mayor matiz, las prácticas del espiritismo ${ }^{2}$ y la religión católica (Nervo 11), esta última capaz de hacer referencia a una teología, aspecto del cual el primero simplemente carece.

Alguna vez su punto de partida, antes de que la plegaria trasmutada en poesía se emancipara de las ceremonias en torno a lo divino y su culto, la religión atraviesa la literatura aunque muchas veces solapada (o confundida) con lo fantástico. En el caso que nos ocupa, el cuento "La verdad", del escritor mexicano Alberto Chimal (Toluca, 1970), el traslape entre el cuento y los postulados de la filosofía de la religión es evidente, como esperamos demostrar.

Por lo tanto, haremos una exposición, necesariamente breve, dada su complejidad, de la filosofía materialista de la religión a la cual nos atenemos, aquella construida por el español Gustavo Bueno (Santo Domingo de la Calzada, 1924) y que puede encontrarse abordada de forma plena en su libro El animal divino (1985), así como en otros de sus volúmenes, como Cuestiones cuodlibetales en torno a dios y la religión (1989) y La fe del ateo (2007), además de los numerosos artículos que se han publicado en torno a las polémicas suscitadas acerca de lo que se conoce como la verdad de las religiones primarias, ${ }^{3}$ algo que explicaremos más adelante. Bueno es, al menos desde los años setenta del siglo pasado, el constructor de todo un sistema, el materialismo filosófico, mismo que no ha dejado de lado prácticamente ninguna parcela del saber, con varias obras en las cuales aborda la importancia de los mitos en la construcción de la realidad. Estamos ante un proyecto en el cual la filosofía de la religión ocupa un lugar preponderante, por las razones a las cuales hacíamos referencia desde un principio.

\footnotetext{
${ }^{2}$ Más adelante citaremos una breve crítica, desde la filosofía materialista, de lo que llamaremos "espiritualismo mundano" (Bueno, Ensayos 28).

${ }^{3}$ El lector interesado puede acceder al índice de polémicas de la revista española de filosofía El Catoblepas para conocer el dilatado debate que se llevó a cabo, entre 2003 y 2005, bajo el rótulo "sobre la verdad de las religiones primarias".
} 
Para empezar, veremos cómo este filósofo determina la esencia de la religión, para lo cual pone en consideración una doctrina de la esencia procesual. De acuerdo con la teoría de la esencia genérica, que Bueno expone en El animal divino (107-14), cuando se trata de fenómenos religiosos no resulta adecuado clasificar estos de acuerdo con las esencias porfirianas, que nos exigirían establecer con excesivo rigor un género y a continuación especies independientes entre sí que reproducirían de forma unívoca la estructura del género: “El género 'poliedro regular' se especifica distributivamente en las cinco especies de poliedros regulares, tales que cabrá hablar de una participación inmediata del género en cada especie con independencia de las demás especies (la especie dodecaedro puede ser concebida o moldeada independientemente de la especie hexaedro)". ${ }^{4}$ Vamos a ver que Bueno hablará en cambio de una esencia genérica, una totalidad sistemática que se expresa mediante el desarrollo más bien heterogéneo de sus partes, un desarrollo procesual que puede incluso alcanzar la negación de la esencia. De esa forma, frente a las esencias porfirianas vamos a contraponer las esencias plotinianas:

En otras ocasiones denominamos "esencias plotinianas" (especies plotinianas, géneros plotinianos, \&c.) -contraponiéndolos a las "esencias porfirianas" (esencias constituidas por la composición de un género próximo y una diferencia específica) - a aquellas totalidades evolutivas o transformativas que se desenvuelven según líneas muy heterogéneas, sin perjuicio de la unidad dada en su misma transformación (Plotino, Enéadas, VI, 1, 3: "La raza de los heráclidas forma un género, no porque tengan un carácter común, sino por proceder de un sólo tronco") (Bueno, Animal 111).

De esa forma, la esencia genérica comprenderá a su vez varios momentos, que son precisamente muestra de su desarrollo. Así, ha-

\footnotetext{
${ }^{4}$ Ver la entrada "Totalidades diatéticas / Totalidades adiatéticas" del Diccionario filosófico de Pelayo García Sierra.
} 
blaremos de un núcleo, de donde mana la esencia, justo el que permite hablar de una esencia genérica, incluso en aquellas partes en las cuales el núcleo haya sido desechado. El núcleo a su vez proviene de un "género generador", del cual habría surgido a partir de un proceso de anamórfosis, es decir, la constitución de una realidad novedosa a partir de la recombinación de realidades previas. ${ }^{5}$

Luego, el núcleo interactúa con su entorno, en la medida en que del núcleo mismo surgen determinaciones de la esencia que van formando una "corteza". Estamos ante el cuerpo, cuyo crecimiento podemos atestiguar en la formación de varias capas acumulativas; así, el cuerpo surge del núcleo y a su vez lo condiciona. Sin embargo, el núcleo va cambiando, lo cual da lugar a la evolución de la esencia. Surgen así las fases de la esencia genérica que, en su conjunto, llamaremos aquí curso. Tenemos, por lo tanto, un núcleo, un cuerpo y un curso de la esencia genérica. De acuerdo con esta doctrina, la esencia procesual jamás podrá ser reducida al núcleo, porque cuerpo y curso también son esenciales: la esencia aparece en el proceso de cada una de sus determinaciones concretas. Veamos ahora como se aplica lo anterior a la filosofía de la religión de Bueno, el materialismo religioso.

Antes, unas palabras en torno a la ontología de Gustavo Bueno, como se expone en el volumen Ensayos materialistas (1972), que suele considerarse su obra seminal. Es en este libro donde Bueno comparte su idea de materia, con tres géneros de materialidad: las materialidades físicas, ${ }^{6}$ los objetos tangibles a los cuales hace refe-

${ }^{5}$ Ejemplos de anamórfosis son los escenarios hipotéticos de la fantasía heroica, como la Tierra Media de Tolkien o Terramar de Ursula K. Le Guin, surgidos ambos a partir de la reformulación de la Edad Media, en la medida en que las instituciones de esta (como el duelo singular y las armaduras, los castillos y las espadas con nombre) también se re-presentan en la ficción. Es decir, la Tierra Media no emergió de la nada, sino que se constituyó a partir de la variación de una realidad previa.

${ }^{6}$ En Ensayos materialistas, Bueno explica que el espiritualismo no es sino una variante del materialismo corporeísta, desde que aquel "adorna con atributos morales y estéticos al estado gaseoso de las substancias materiales” (Bueno, 
rencia el materialismo corporeísta (M1); en segundo lugar tenemos las sensaciones, la psicología (M2) y, finalmente, los objetos abstractos (M3), como los números naturales.

Para los fines de este artículo hay que decir que Bueno, además, ha determinado de forma crítica el área de acción de la antropología, para lo cual ha desarrollado el concepto de espacio antropológico, para él tridimensional y que por lo tanto ha sistematizado de la manera que exponemos enseguida. Hay, primero, un eje circular del espacio antropológico en el cual tiene lugar la inmanencia de lo humano (que Bueno denomina sujeto operatorio) y sus semejantes. En el eje radial hay que ubicar esos contenidos de naturaleza no humana que sin embargo son contemplados por la antropología, como puede ejemplificarse en el caso del medio astronómico, de gran importancia al momento de imbricarse en los mitos del tipo de la Teogonía, por ejemplo. Tradicionalmente, como se sabe, se ha reivindicado un espacio bidimensional (el Hombre frente a la Naturaleza), de ahí que Bueno introduzca un tercer eje, el angular, en el cual el sujeto operatorio establece relaciones con entidades que también son subjetuales, como es el caso de los dioses, que no son una mera alucinación de los hombres en el eje circular aunque con ello Bueno (un filósofo ateo) no reconoce su existencia, como veremos. Lo que ocurre es que Bueno identificará ciertos animales linneanos como númenes ${ }^{7}$ dotados de voluntad y capaces de entablar relaciones de dominación con el hombre, quien en el Paleolítico representaba (como puede comprobarse en las cuevas de Altamira) a ciertas especies como objeto de adoración, una práctica que alcanzó su decadencia con la revolución neolítica y la domesticación de las bestias, es decir, la derrota de los antiguos dioses

Ensayos 28). De ahí que en el cine "fantástico" contemporáneo se represente a los fantasmas como si estuvieran formados por moléculas de gas, lo cual quiere decir que quienes han perpetrado esas historias muy probablemente asocian la materia exclusivamente con el corporeísmo. Estamos ante un materialismo mundano y sumamente reduccionista.

${ }^{7}$ El diccionario en línea de la RAE define numen de la siguiente forma: "Deidad dotada de un poder misterioso y fascinador". 
(lo que no implica que lo que se llamará religión primaria no pueda tener cierta persistencia ${ }^{8}$ ). De ahí que este autor sitúe el núcleo de la religión precisamente en los animales, al mismo tiempo que rechaza la posibilidad, por falsaria, de vivientes incorpóreos, como los ángeles y los demonios, mientras que el tigre dientes de sable, por ejemplo, será clasificado como una criatura numinosa. Algo que puede resumirse en la consigna del materialismo filosófico: "El hombre hizo a sus dioses a imagen y semejanza de los animales". El hombre será interlocutor de la religación entre él y los animales.

Muy importante es tener en cuenta que no hablamos de que el hombre haya divinizado a ciertos animales, sino que estos son "los núcleos numinosos de la propia Idea ulterior de divinidad". Así, Bueno puede hablar de una religión verdadera, porque los animales a los cuales esta hace referencias son reales (184), bestias concretas y rotundas, megafauna; eso sí, ahora por completo extinta, una de las causas de la decadencia de este tipo de religión. Estos dioses animales son, por lo tanto, reales, porque con ellos se entabló una cruenta lucha por la sobrevivencia.

Nos internamos en el ámbito de la religión primaria o nuclear, que podemos encontrar representada (o problematizada) en la literatura en cuentos como "Una cacería trágica" (1920), de José Vasconcelos (Llanes 2014), así como en novelas del talante de Sorgo rojo (1987), del Nobel Mo Yan, en la cual una jauría se organiza a la ma-

\footnotetext{
${ }^{8}$ Precisamente eso es lo que se aprecia en la popularidad del animalismo en la actualidad, así como extravagancias como la creencia en seres de otros planetas. Como explicábamos en una nota anterior, estamos ante una refluencia, el volver a fluir de corrientes antes retenidas por el cristianismo. A este respecto dice Bueno: "De este modo se nos manifiesta la inesperada afinidad entre este renacimiento del interés por los extraterrestres y el renacimiento del interés y de la piedad por los animales. Ufología y Etología consideradas desde la perspectiva de una filosofía de la religión como la que estamos esbozando, se nos presentan como dos consecuencias - una, en el terreno de la ciencia ficción y otra en el terreno de la ciencia estricta- del mismo proceso; a saber, el retorno a las formas de religiosidad secundarias o primarias, una vez que la religiosidad terciaria, en la forma del antropocentrismo cristiano exasperado, parece haber agotado sus posibilidades creadoras" (Bueno, Animal 294).
} 
nera de un ejército que desafía a los hombres. En ambos vamos a ver que entre los animales y el hombre hay una religación altamente conflictiva cuyas claves se encuentran precisamente en las referencias a la religión primaria, con unos animales que hacen alarde de su fuerza para interactuar de forma no precisamente pacífica con el hombre, su devoto y al mismo tiempo antagonista.

Estamos, así, ante una filosofía de la religión, que pone "la verdad nuclear de los númenes fenomenológicos en sus referencias animales reales" y, por lo tanto, hablamos de una teoría angular (zoomórfica) de la religión (Bueno, Animal 168), porque es precisamente en el eje angular del espacio antropológico donde el hombre se relaciona, de forma muy diversa, con los animales.

Posteriormente, se hablará de religión secundaria (o mitológica), cuando los animales pasen a integrarse a los signos del zodiaco y aparezcan, como protagonistas, en las ceremonias de dioses antropomórficos, como en el antiguo Egipto o en la mitología griega. Nos situamos en la etapa comúnmente denominada politeísta, que habrá de chocar con la religión primaria como puede verse en "Los caballos de Abdera”, de Leopoldo Lugones (Llanes 2013), en el cual es Hércules (religión secundaria) el encargado de derrotar a los soberbios equinos que se han rebelado violentamente de sus amos (religión primaria).

Por último, haremos mención de la religión terciaria o metafísica. O bien, como suele decirse desde el reduccionismo, la correspondiente a las religiones del libro o monoteístas, como el judaísmo, el catolicismo y el islam. Innumerables podrían ser los ejemplos que, entre nosotros, podemos citar de obras literarias que hacen referencia a la religión terciaria: pienso en el "pueblo de mujeres enlutadas”, de Agustín Yáñez, o bien en el padre Rentería de Pedro Páramo. Tenemos entonces un curso de la religión, formado precisamente por esas fases de las religiones: primaria, secundaria y terciaria.

El cuerpo de la religión habrá que especificarlo en cada caso, en referencia a las instituciones, en sentido antropológico, que constituyen el culto, como ocurre con el animal numinoso de la religión primaria y el fetiche que lo representa (Bueno, Animal 298-99), así como las danzas y los cánticos (300) y normas de conducta como el 
tabú (301). Cuando analicemos el cuento de Chimal, veremos con más claridad ejemplos del cuerpo de la religión primaria, porque ese es precisamente uno de los detalles de la historia. De hecho la ficción quedará incorporada al culto. En la religión secundaria, el cuerpo hará referencia a los templos y, algo muy importante, la noción de sacerdote como especialista religioso (303). Ejemplos del cuerpo de la religión terciaria los podemos encontrar en "el desinterés por el mundo físico como 'valle de lágrimas' y lugar de paso", así como en la profundización de "las categorías de pecado y culpa": "Todo ello, unido a un despliegue masivo y tecnológico de la liturgia, del arte sagrado, de la arquitectura y la música sacra” (308). Citamos ciertas instituciones a manera de ejemplo aunque, como hemos dicho, habría que abordar cada caso en particular y aquí no lo hacemos de manera exhaustiva. No obstante, resulta conveniente llamar la atención a propósito de los templos y el papel que juegan como constitutivos del cuerpo a lo largo del curso de las religiones, porque eso nos permite ver cómo va evolucionando: el dios de las religiones primarias tendrá un lugar sagrado, aquel donde está depositado el fetiche (una cueva, por ejemplo), mientras que los dioses mitológicos no tienen que estar confinados en el templo:

Un lugar sagrado, reforzado por un edificio, aunque en apariencia sería un templo, sólo se diferenciará del lugar sagrado primario por motivos extrarreligiosos, a saber, el desarrollo de la tecnología arquitectónica. En efecto, en tanto que los númenes primarios se han transformado en dioses, ya no están confinados a un babitáculo, nicho o guarida finitos (porque los establos o las granjas reales, aunque contienen a los antiguos númenes, ya no serán, en general, templos, al perder sus inquilinos el coeficiente numinoso). Los dioses han llegado a habitar lugares celestiales, inaccesibles, o incluso inaccesibles lugares terrestres o marítimos (Bueno, Animal 302).

Por lo tanto, el templo deja de ser la casa de los dioses secundarios, sin perjuicio de que pueda servir como el lugar en el cual estos aparecen ante sus fieles (302). En la fase terciaria, ya no podrá hablar- 
se ni siquiera de eso, "posadas de los dioses", en tanto que se habla de la totalidad del universo como "Templo de Dios". Un dios que no está limitado a morada alguna porque encuentra su templo "en el corazón de los hombres" (305). En la teoría del templo podemos encontrar una ilustración bastante clara, decíamos, de los cambios que se suscitan en el cuerpo de las diferentes religiones.

Como ocurre con la religión, el mito es fundamental para nuestro análisis. En uno de sus ensayos, José Luis Martínez se refirió a "aquella condición esencial de la literatura que es la ficción" (76). Así, encontraremos que se echa mano de la ficción literaria para construir mitos, de forma ejemplar en el cuento que analizamos. Al respecto del mito y sus implicaciones, es fundamental la lectura de lo dicho por Bueno (Izquierda 12-15), quien asegura que el mito ya es un logos, cuando tradicionalmente ambas cosas se han opuesto. Por ejemplo, afirmar que la Tierra está sostenida por Atlas supone una cierta sofisticación del pensamiento, necesaria para intuir que hace falta una fuerza para evitar que el planeta caiga al vacío. En la Antigüedad no se habla de gravedad aunque en cambio se reconoce que la Tierra no puede flotar, sin más, en el espacio. Hay mitos que asumen la interpretación del mundo y por lo tanto pueden establecerse efectos generales atribuibles a ellos: 1) Hay mitos luminosos, como el ya citado de Atlas y el de la caverna de Platón. 2) O bien hay mitos oscurantistas, que dificultan la interpretación correcta de un fenómeno. Bueno cita en este último sentido los mitos del Antiguo Testamento, como el de la Torre de Babel. ${ }^{9}$

La relación entre verdad y ficción para muchos es dialéctica, aunque aquí vamos a reivindicar un balance muy distinto. Acerca de uno de los sonetos de Lope de Vega, "Suelta mi manso mayoral ex-

\footnotetext{
${ }^{9}$ En nuestros días podemos hablar del mito de la Izquierda, por ejemplo, que supone acríticamente la unidad de la izquierda política, opuesta sin más a la Derecha, sin tomar en cuenta que, por ejemplo, hay generaciones de izquierda enfrentadas entre sí, como ocurre entre anarquistas y comunistas (Bueno, Izquierda 12-17). Hay muchos otros ejemplos de mitos oscurantistas, como el mito de Europa, que Bueno se ha encargado de triturar a lo largo de su obra.
} 
traño", Gustavo Bueno afirma que si bien no nos lleva a una verdad científica, "sí acaso a alguna aproximación (práctica-empírica, o de experiencia), a alguna verdad de tipo etológico o filosófico", con lo cual quedarían en entredicho las oposiciones entre razón/intuición o razón/sentimiento (Bueno, Poemas), tan caras al romanticismo, por ejemplo. Así, vamos a ver que, en el relato que estudiamos, hay una verdad que si bien no es científica, sí se corresponde con lo defendido por Bueno a propósito del origen de la religión. Esa correspondencia pone de manifiesto que la ficción literaria puede apelar a una verdad de tipo filosófico, en este caso referente a lo que, con Bueno, hemos llamado el núcleo de la religión.

"La verdad"10, el cuento de Alberto Chimal que nos ocupa, cuenta la historia de Amma, "Primera Mujer, Madre de Cuantos Son y Cuantos Serán”, en un tiempo "antes de la invención de la escritura, más allá de toda memoria [,] antes de todos los imperios, de todas las guerras" (Chimal 11). Una noche, Amma está refugiada en una cueva al lado de su pareja, Sembeh: "se ocultaban de las fieras que les disputaban el mundo; podían oírlas, acechando cerca de la entrada de la cueva: el lobo, el leopardo, el oso..., toda la vida que no duerme al irse el sol y en verdad no nos ama" (Chimal 11-12) (Las cursivas son nuestras). Escuchan un "sonido terrible": "Un ulular, una voz que no era humana", que aterra al desconsolado varón: "Sembeh ... lamentó la impotencia del hombre ..., que no tenía pelo espeso para calentarse, ni largos colmillos ni la fuerza del elefante ni la facultad de volar, que tanto sirve al buitre y al águila" (12).

Como puede verse, el cuento está situado en un período al menos análogo al que ubicamos como el del auge de la religión primaria, el correspondiente al de la supremacía de los animales, como queda claro en el lamento de Sembeh, asustado por una fuerza des-

${ }^{10}$ Citamos por la versión original del cuento, publicada en 2001, en el volumen El país de los hablistas. En 2012, Antonio Jiménez Morato lo recogió en la antología de los cuentos de Chimal publicada en España, Siete (en la editorial Salto de página). 
conocida y al mismo tiempo anhelante de las habilidades de las bestias. De ahí que Sembeh se desespere y comience a patalear y a gritar como un niño, temeroso de la muerte. Su mujer trata de calmarlo pero cuando fracasa, fastidiada, para hacerlo callar le cuenta a su hombre una historia para explicar el origen del estruendo que tanto los sorprende:

¿Sabes qué es? Es una araña, Sembeh. Es una araña negra, enorme, de ocho patas tan altas como alta es tu cabeza, ojos rojos y brillantes como la lava, garras de piedra en cada pata, colmillos venenosos, el corazón negro y malvado y esa voz que escuchamos, que es terrible pues en verdad cuadra a su cometido de traernos la muerte, y perseguirnos a donde quiera que vayamos, a menos que le hagamos frente. Pero vencerla es imposible (13-14).

La araña, entonces, es más fuerte que el hombre y este hace bien en temerle, porque su tarea sobre la tierra es ocasionar la muerte y no se puede huir de ella. Pero Amma, la primera mujer, no ha terminado con su discurso: "Sólo si le rindes pleitesía se aplaca, pues cree que el mundo le pertenece y nosotros con él. Hasta la luz y la oscuridad le temen. Y por más que le ofrezcas, por más que te humilles ante ella, siempre será sólo un aplazamiento de que te ataque y caiga sobre ti para romperte la espalda y abrirte el pecho y beberse tu sangre" (14).

Amma no lo sabe, desde luego, pero en el relato acaba de propiciar un fenómeno propio de la religión primaria. A partir de ese día, Sembeh derrotará su inicial terror por la bestia y se convertirá en su primer protosacerdote, ${ }^{11}$ entusiasta y fanático, para luego despreciar a su mujer, que quedará proscrita de las prácticas en torno a la araña

\footnotetext{
${ }^{11}$ Bueno explica que en cuanto a la religión secundaria todavía no se puede hablar de especialistas, sacerdotes en sentido estricto (como no se puede hablar de templos), de ahí que se remita a protosacerdotes, que bien puede ser brujos, hechiceros o chamanes (300).
} 
divina y sus deseos; en esa segregación de Amma, por ejemplo, ya reconocemos uno de los componentes del cuerpo de la religión primaria, en tanto que norma de conducta. Por medio de la ficción, Sembeh le da forma a la mitología en torno a la araña:

la cabeza dura de Sembeh se llenaba de historias, y su boca no hablaba sólo de la araña, que de pronto era más antigua que el mundo mismo, y dueña de fuerza inmensurable y toda la sabiduría: además, Sembeh le inventó hazañas, discursos, cantos y diatribas, e imaginó también a otras muchas criaturas poderosas, con ese nombre extraño de dioses y potestad sobre lo grande, lo peligroso, lo desconocido (16).

Sembeh pone en pie, de acuerdo con la terminología que hemos explicado antes, un mito oscurantista, porque este le permite segregar a su mujer, crítica del culto, como indigna de la araña: "¿Cuándo has oído lamentarse a una araña?" (16), pregunta la incrédula, desesperada. Sin embargo, la religión que reivindica no es una mera alucinación, una relación imposible entre dios y el hombre, sino que parte de un animal real, la araña, propuesta como numen. Una araña fabulosa, es cierto, dotada en el mito de poderes falsarios, pero araña al fin y no ángel, demonio o espíritu errante, viviente incorpóreo o inteligencia separada; por el contrario, en voz de Sembeh, Amma (cuando finalmente se rinde a la ficción) y el hijo de ambos, Massih, proliferan las bestias de la religión primaria: el toro del sol, el oso del fuego, el gran gusano... (17-18).

Las palabras finales del cuento inciden de nuevo en la esencia de lo literario, la ficción. Amma es llamada "Madre de las Historias y de Quienes las Cuentan: de quienes decimos la verdad para que nadie la oiga, y mentimos para instaurar el universo" (18). Por medio de la ficción se construyen mitos de gran fortaleza, como aquellos que gravitan en torno de lo religioso. Además, Bueno se pregunta cómo fue que los animales llegaron a convertirse en númenes, es decir, cómo es que se formó la religión primaria. Uno de los elementos que intervinieron en ese proceso fue, nos dice, "el factor lingüístico estricto, es decir, el lenguaje fonético articu- 
lado", porque "los mitos o relatos narrados en las largas noches de las cavernas son seguramente el complemento indispensable de las figuras animales pintadas en sus paredes e iluminadas por las antorchas" (Bueno, Animal 244).

Concluimos: como puede verse, "La verdad" ilustra desde la ficción literaria la filosofía de la religión de Gustavo Bueno, cuando muestra el desarrollo de la religión primaria no en el mero psicologismo del hombre y su necesidad imperiosa de opio del pueblo, sino en las bestias ante las cuales alguna vez se arrodilló el primitivo, con la ficción como tributo en el altar de un dios que inspira las viejas historias.

\section{Obras consultadas}

Bueno, Gustavo. Ensayos materialistas. Madrid: Taurus, 1972.

- "Sobre el concepto de espacio antropológico". El Basilisco 5 (1978): 57-69. PDF.

- El animal divino. Ensayo de una filosofía materialista de la religión. España: Pentalfa Ediciones, 1996. Impr.

—. El mito de la iqquierda. España: Ediciones B, 2006. Impr.

—_. "Poemas y Teoremas". El Catoblepas 88. (2009). Web. 23 sep. 2013.

Chimal, Alberto. El país de los hablistas. México: Libros del Umbral, 2001. Impr.

Llanes García, Manuel. "Religión secundaria en 'Los caballos de Abdera”. El Catoblepas 142 (2013). Web. 23 sep. 2013.

— . "Religión primaria y caza angular en un cuento de Vasconcelos". El Catoblepas 147. (2014). Web. 23 sep. 2013.

Martínez, José Luis. Problemas literarios. México: Conaculta, 1997. Impr.

Nervo, Amado. El castillo de lo inconsciente. México: Conaculta, 2000. Impr.

Vasconcelos, José. La sonata mágica. México: Espasa-Calpe, 1950. Impr. 